\title{
ESTRATÉGIAS DE ENFRENTAMENTO E O SOFRIMENTO DE MÃES DE FILHOS COM PARALISIA CEREBRAL
}

PAIN AND COPING STRATEGIES OF MOTHERS OF CHILDREN WITH CEREBRAL PALSY

Recibido: 20 de Mayo del 2015 | Aceptado: 15 de Diciembre del 2015

\author{
ANGÉLICA OLIVEIRA NASCIMENTO ${ }_{1}$; ANDRÉ FARO 2 \\ (UNIVERSIDADE FEDERAL DE SERGIPE, UFS Sergipe, Brasil)
}

\begin{abstract}
RESUMO
Objetivo: identificar as mudanças ocorridas na vida de mães cuidadoras de crianças e adolescentes com paralisia cerebral, impactos e estratégias de enfrentamento desenvolvidas por elas na trajetória do cuidado. Métodos: Foram entrevistadas onze mães, cujos filhos estavam entre sete e dezoito anos, matriculados em uma unidade de ensino da rede estadual brasileira. Utilizaram-se entrevistas semiabertas, analisadas por meio do programa IRAMUTEQ e baseadas em cinco eixos temáticos: momento do diagnóstico; informações da equipe de saúde; mudanças na vida da mãe e na dinâmica familiar; momentos mais difíceis; suporte social e apoio da família. Resultados: As mães sofrem os primeiros impactos no momento do nascimento e na confirmação do diagnóstico, além do que se identificou que a família é o principal suporte das mães. Percebeu-se a necessidade de maiores esclarecimentos para as mães sobre a paralisia cerebral por parte da equipe de saúde nos primeiros momentos de vida da criança, como também, foram apontadas como causas de sofrimento a discriminação e a rejeição por parte da sociedade. Conclusao: 0 papel de cuidadora pode ser desgastante e desencadear adoecimento físico e psíquico e, diante disso, reitera-se a necessidade de cuidado ao cuidador na paralisia cerebral infantil.
\end{abstract}

PALAVRAS-CHAVE: Paralisia cerebral; cuidador; estratégias de enfrentamento.

\section{ABSTRACT}

Objective: This research aimed to identify the lifestyle changes of mothers whose children suffer from cerebral palsy, as well mothers' coping strategies and their effectiveness during the years of care. Method: Eleven mothers whose children's age ranked between seven and eighteen and who had been enrolled in a Brazilian educational unit were interviewed. Semi-structured interviews were used to collect the data. They were analyzed using the IRAMUTEQ program. These interviews were based on five topics: time of diagnosis, health team information, changes in mothers' and families' lifestyle, most difficult times; social support and family support. Results: Results mainly revealed two situations: 1. Mothers' first and hardest impact is at birth and at the time of diagnosis confirmation; 2. Mothers' main support is family. Also, it is important to highlight, on the one hand, that mothers need to be provided with more clear information about cerebral palsy by health professionals during the child's first years of life; on the other, that social rejection and discrimination constitute sources of pain and sorrow for mothers. Conclusions: The role of mothers (understood as caregivers) may be exhausting and could cause physical and mental illness. Therefore, caregivers of patients with cerebral palsy must be medically assisted too.

Keywords: Cerebral palsy, caregiver, coping strategies

KEY WORDS: Cerebral palsy, caregiver, coping strategies. 
Para algumas pessoas, a Paralisia Cerebral (PC) ainda é considerada uma patologia, mas a definição mais adotada pelos especialistas vem de 1964 e a caracteriza como um "distúrbio permanente que provoca deficiência nos movimentos e na postura, devido à lesão não progressiva no cérebro, no começo da vida" (Leite \& Prado, 2004, p. 41). A PC é também concebida como um distúrbio motor provocado por lesão cerebral (Petean \& Murata, 2000). Logo, existem várias definições, mas, sabese que por ser irreversível, recorrente, de longa duração e que demanda cuidados especiais, ela é considerada, prioritariamente, uma condição crônica (Baltor \& Dupas, 2013).

Em números, a maior incidência de casos de PC encontra-se nos países subdesenvolvidos (Mancini, Fiúza, Rabelo, Magalhães, Coelho, Paixão et al., 2002). Estima-se que no Brasil anualmente de 30.000 a 40.000 crianças sejam afetadas pela PC. Nos últimos anos houve um aumento no percentual de crianças afetadas e 0 fato parece estar relacionado a problemas gestacionais, precárias condições de nutrição das mães, falta de acompanhamento pré-natal, parto natural forçado e más condições de atendimento médico e hospitalar. Além disso, sabe-se que crianças que nascem com peso abaixo de $1500 \mathrm{~g}$ sofrem disfunções neurológicas com maior frequência do que as que nascem com peso normal (Mancini et al., 2002; Silva, Brito, Sousa, \& França, 2010).

Como características gerais, a PC apresenta a espasticidade muscular, que gera na criança dificuldades de realizar atividades simples (Silva et al., 2010). As limitações vão desde o simples ato de tomar banho, vestir-se, alimentar-se sozinho, entre outras, além das atividades sociais e cognitivas, como interação com outras crianças, brincar e frequentar a escola. Tais atividades são essenciais na vida dos seres humanos, especialmente na infância, sendo assim, a incapacidade de desenvolvê-las acarreta sérias dificuldades tanto para a criança, quanto para 0 seu cuidador (Mancini et al., 2002).

A PC pode ser classificada seguindo dois critérios: pela disfunção neuromotora apresentada, incluindo os tipos extrapiramidal ou discinético, atáxico, espástico e misto; e pelo comprometimento na região do corpo, que inclui a monoplegia, hemiplegia, diplegia, paraplegia, tetraplegia ou quadriplegia. $\mathrm{Na} \mathrm{PC}, 88 \%$ dos casos são do tipo espástico, em que ocorre a rigidez muscular. Quanto à localização do corpo, a hemiplegia é a manifestação mais frequente, com maior comprometimento dos membros superiores (Leite \& Prado, 2004). Porém, salienta-se que por ser uma condição neuromotora que compromete 0 desenvolvimento e requer cuidados especiais, a PC, independentemente da classificação, traz algum comprometimento das funções em menor ou maior grau, podendo se agravar ou minimizar a depender do caso e dos cuidados (Jaques, Drumond, Andrade, Junior, \& Tofoll, 2010).

Tornar-se um familiar cuidador de pessoas com doenças crônicas, tem sido uma prática muito comum, visto que a expectativa de vida tem aumentado, juntamente com o número de pessoas que necessitam de cuidados (Ferreira, Martina, Braga, \& Garcia, 2012). O encargo de cuidador exige muito do indivíduo e desencadeia mudanças em seu cotidiano, sendo necessários diversos reajustes imprescindíveis no seu dia-dia, o que influencia não apenas a forma pela qual executa o cuidado, mas pesa notoriamente em sua própria vida (Fonseca, Penna, \& Soares, 2008; Krstic \& Oros, 2012; Wijesinghe, Hewage, \& Fonseka, 2014). Usualmente, o papel de cuidador é dirigido a um único familiar, sendo mais comum uma mulher, nos papéis de filha, esposa ou mãe (Ahmadizadeh \& Mokhlesin, 2014; Godim, Pinheiro, \& Carvalho, 2009). 
Quando se trata de crianças com PC, é quase consensual encontrar mães como principais cuidadoras e isso parece se repetir em diferentes culturas (Ahmadizadeh, Rassafiani, Khalili, \& Mirmohammadkhani, 2015; Camargos, Lacerda, Viana, Pinto, \& Fonseca, 2009; Krstic \& Oros, 2012; Manuel, Naughton, Balkrishnan, Smith, \& Koman, 2003; Marrón et al., 2013; Ones, Yilmaz, Cetinkaya, \& Caglar, 2005; Wijesinghe et al., 2014). 0 papel de cuidadora e protetora do lar, geralmente atribuído à figura feminina, está relacionado a fatores históricos e sociais, que situou a mulher como responsável pela organização da casa e cuidados com a família (Camargo, 2010; Silva et al., 2010).

As mudanças ocasionadas na vida do cuidador são comumente relacionadas à rotina de acompanhamento clínico, administração de medicamentos, dietas, banho, dentre outras questões. Todo esse tempo de dedicação, que é praticamente exclusiva, tende a se configurar como estressores, pois pode gerar, como em qualquer atividade cuja responsabilidade é elevada, estresse crônico na pessoa que cuida (Ahmadizadeh \& Mokhlesin, 2014; Brehaut et al., 2004; Manuel et al., 2003; Silva et al., 2010).

A sobrecarga relacionada ao cuidado de uma criança portadora de doenças crônicas limitante do desenvolvimento, tal como a $\mathrm{PC}$, tende a gerar impactos e consequentes desgastes, no cotidiano da vida familiar, em particular no principal cuidador, pois este está diretamente envolvido com os desafios do cuidado (Baltor \& Dupas, 2013; Krstic \& Oros, 2012; Marrón et al., 2013). Na PC os impactos são derivados de uma rotina desgastante físico e emocional onde quem cuida necessita de preparo físico, por exemplo, para deslocar a criança de um local para outro, pois, de acordo com o grau da lesão, cerebral a criança depende totalmente do cuidador para se locomover, alimentar-se, tomar banho e realizar as necessidades básicas (Lazcano, Cura,
Aranda, Heras, Elizondo, \& Garza, 2014; Mancini et al., 2002; Simões, Silva, Santos, Misko, \& Bousso, 2013). Emocionalmente, a mãe sofre desde o diagnóstico (Simões et al., 2013) e daí surgem o medo de não saber cuidar, a vergonha, a preocupação com o futuro da criança, o sentimento ambivalente de superproteção, culpa e luto pelo filho que não nasceu perfeito (Barbosa \& Oliveira, 2008).

0 enfrentamento consiste nas estratégias desenvolvidas pelos indivíduos para lidar com situações impactantes que fogem da sua capacidade de suportar ou solucionar. São situações consideradas ameaçadoras e que demandam mudanças na vida das pessoas e reajustes cognitivos e psicológicos (Kohlsdorf \& Costa Junior, 2008). A forma de enfrentamento das adversidades do cuidador irá variar de indivíduo para indivíduo, podendo ser encarada de uma maneira menos impactante para um sujeito, mas pode ser altamente danosa para outro. Os desafios do cuidar e as formas de encarar o cotidiano também diferem de acordo com as experiências de vida de cada cuidador, do contexto social em que a pessoa se encontra inserida, da sua condição financeira e do apoio social e familiar (Barbosa \& Oliveira, 2008; Manuel et al., 2003; Matsukura, Marturano, Oishi, \& Borasche, 2007).

0 processo de enfrentamento sempre ocorre, ainda que varie entre desfechos adaptativos e não adaptativos (Simões et al., 2013). Como ilustração, Krstic e Oros (2012), entre mães sérvias cuidadoras de filhos com PC, constataram que a estratégia da ressignificação do cuidado se mostrou como a mais efetiva na redução do estresse. Já Ahmadizadeh et al. (2015) viram que entre mães iranianas uma característica que favoreceu à adaptação foi a condição de ter um emprego, pois isso permitia a reelaboração do cuidado e menor concentração de estressores ao longo do dia. Por fim, Marrón et al. (2013) relataram que o nível de sobrecarga entre mães 
espanholas era atenuado pelo nível de autoeficácia dessas cuidadoras.

Considerando os exemplos citados, vêse que existem pessoas que desenvolvem mecanismos mais favoráveis à adaptação frente às adversidades do cuidado, ao passo que outras demonstram maior dificuldade em lidar com os mesmos desafios, o que resulta em uma adaptação mais sofrida e estressora, isso porque, nem sempre o cuidador tem a habilidade ou mesmo suporte para desenvolver alternativas mais saudáveis de ajustamento (Ahmadizadeh \& Mokhlesin, 2014; Bayrakli \& Kaner, 2012; Manuel et al., 2003; Ribeiro, Porto, \& Vandenberghe, 2013). Logo, pesquisas nesse campo são importantes, visto que ainda se carece de maior atenção à saúde de familiares cuidadores de crianças com doenças crônicas como a PC (Baltor \& Dupas, 2013; Ribeiro et al., 2013; Simões et al., 2013; Whittingham, Sanders, McKinlay, \& Boyd, 2014) e a redução do estresse nesses indivíduos tende a ter um impacto positivo sobre a adaptação das próprias crianças e adolescentes com PC (Ahmadizadeh et al., 2015; Calver et al., 2015).

Assim, diante da forma como as mães lidam com seus filhos e de acordo com os mecanismos de enfrentamento utilizados, julga-se mais provável 0 desenvolvimento de treinamentos de suporte com o intuito de minimizar os impactos resultantes da sobrecarga nas mães de crianças com PC. Enfim, 0 objetivo desta pesquisa foi identificar as mudanças ocorridas na vida de mães cuidadoras de crianças e adolescentes com Paralisia Cerebral, quais os impactos e as estratégias de enfrentamento desenvolvidas por elas na trajetória do cuidado.

\section{MÉTODO \\ Participantes}

Inicialmente, obteve-se a autorização de pesquisa de uma escola de nível fundamental, ligada à rede pública de ensino e situada em pública de ensino e situada em municipio de Aracaju. Essa instituição foi escolhida por meio do critério da conveniência, pois tinha como característica básica a inclusão de alunos portadores de necessidades especiais na rotina regular, mesmo antes da promulgação da Lei Brasileira de Inclusão da Pessoa com Deficiência ( $n^{0}$ 13.146) (Brasil, 2015), que assegura a inserção escolar dessas crianças.

À época da coleta, quinze crianças com PC eram assistidas em diferentes turnos, sendo que quatro a frequentavam pela manhã e sete à tarde. A priori, após apresentações do objetivo da pesquisa à coordenadora da instituição, catorze mães foram selecionadas para convite à participação, mediante 0 atendimento aos seguintes critérios de seleção: seus filhos deveriam ter até dezoito anos e a PC teria que ser diagnosticada como congênita.

Embora as catorze mães constantes na lista inicial tenham sido convidadas, apenas onze responderam ao chamado dos pesquisadores, o que se deu por contato telefônico e pessoalmente. As mães que aceitaram participar tinham idades entre vinte e nove e quarenta e oito anos, com todas situando-se no status socioeconômico baixo (cerca de dois salários mínimos). Oito declararam-se casadas e três afirmaram terem sido abandonadas pelo pai da criança logo após o nascimento do filho com PC, mas que no momento da entrevista estavam em novo relacionamento conjugal.

Quanto aos filhos, foram oito do sexo masculino e três do feminino, com idades entre sete e dezoito anos, sendo um por mãe participante. Em relação ao quadro clínico, todos foram diagnosticados com PC em nível severo e tipo espástica. Devido à gravidade da lesão cerebral, oito eram totalmente dependentes das mães e apenas três conseguiam andar com ajuda do cuidador. 
Instrumentos e Procedimentos

O projeto de pesquisa foi aprovado pelo Comitê de Ética em Pesquisa da universidade Federal de Sergipe (CAAE). A coordenação da instituição forneceu a autorização para a realização da pesquisa e, também, um espaço exclusivo para a realização das entrevistas individuais, mediante assinatura de termo específico. Além disso, todas as participantes declararam seu consentimento por meio do Termo de Consentimento Livre e Esclarecido (TCLE).

Com base em uma entrevista semiaberta, a condução teve como base cinco eixos temáticos, a saber:

1. Recebendo o diagnóstico: Neste eixo as perguntas foram conduzidas com o objetivo de se saber sobre a gravidez, o momento do nascimento da criança e o diagnóstico prévio recebido ainda na maternidade;

2. Informações da equipe de saúde: Procurou-se levantar dados sobre a qualidade e satisfação das informações inicialmente obtidas pelas mães no que concerne à paralisia cerebral e os cuidados necessários para pessoas com essa condição;

3. Mudanças na vida da mãe e na dinâmica familiar: Neste momento buscou-se saber das mães como foi a aceitação advinda dos familiares e sua repercussão na vida das mesmas;

4. Momentos mais difíceis: Buscou-se o relato dos momentos de maior dificuldade enfrentados pelas mães durante a trajetória de cuidado do filho;
5. Rede de apoio e o suporte: Foram investigados principalmente os fatores de suporte por parte da família e da sociedade em geral.

Todas as entrevistas foram gravadas em áudio, mediante autorização por escrito, tendo sido realizadas na própria escola. Isso ocorreu, principalmente, pela presença constante das mães para acompanhamento das atividades dos filhos nesse local.

\section{Análises de Dados}

As entrevistas foram analisadas com 0 IRAMUTEQ, por intermédio da aplicação do método de análise léxica e da técnica de Classificação Hierárquica Descendente (CHD). Para a execução da análise, todas as entrevistas foram reunidas em um único corpus, do qual se obtiveram classes de sentido relativas ao objetivo geral do estudo. Tratou-se de uma abordagem quantiqualitativa do material produzido a partir do discurso das mães, assumindo caráter descritivo-exploratório para a investigação dos fenômenos centrais da pesquisa, que foram o enfrentamento materno, contexto e fatores estressores associados ao cuidado na PC.

A CHD possibilita que os segmentos de textos sejam classificados de acordo com a função dos seus respectivos léxicos, desde que contenham semelhanças entre si e vocabulários distintos de outros segmentos. A partir do cruzamento é calculada a aproximação e distanciamento das palavras com testes do qui-quadrado (Camargo \& Justo, 2013). Neste tipo de análise, os dados são dispostos em um dendograma, no qual as relações entre classes podem ser vistas de maneira ilustrativa. As classes lexicais foram agrupadas a partir do dendograma e, dentre elas, as que obtiveram maior valor quiquadrado foram consideradas as mais representativas, ou seja, exibiram maior relação de pertencimento entre palavra e classe. Cada classe recebeu uma nomenclatura conceitual para o grupo de 
palavras obtido através da CHD. Elaborouse, ainda, um discurso simbólico representativo da ideia central da classe, o que foi proposto pelos próprios a partir da análise do possível sentido abstraído pelo conjunto de léxicos.

\section{RESULTADOS E DISCUSSÃO}

A CHD gerou um dendograma de três classes e na Figura 1 estão representadas as classes e as nomenclaturas de cada uma delas.

FIGURA 1.

Dendograma e Classes Léxicas dos Impactos e Estratégias de Enfrentamento de Mães de Filhos com Paralisia Cerebral.

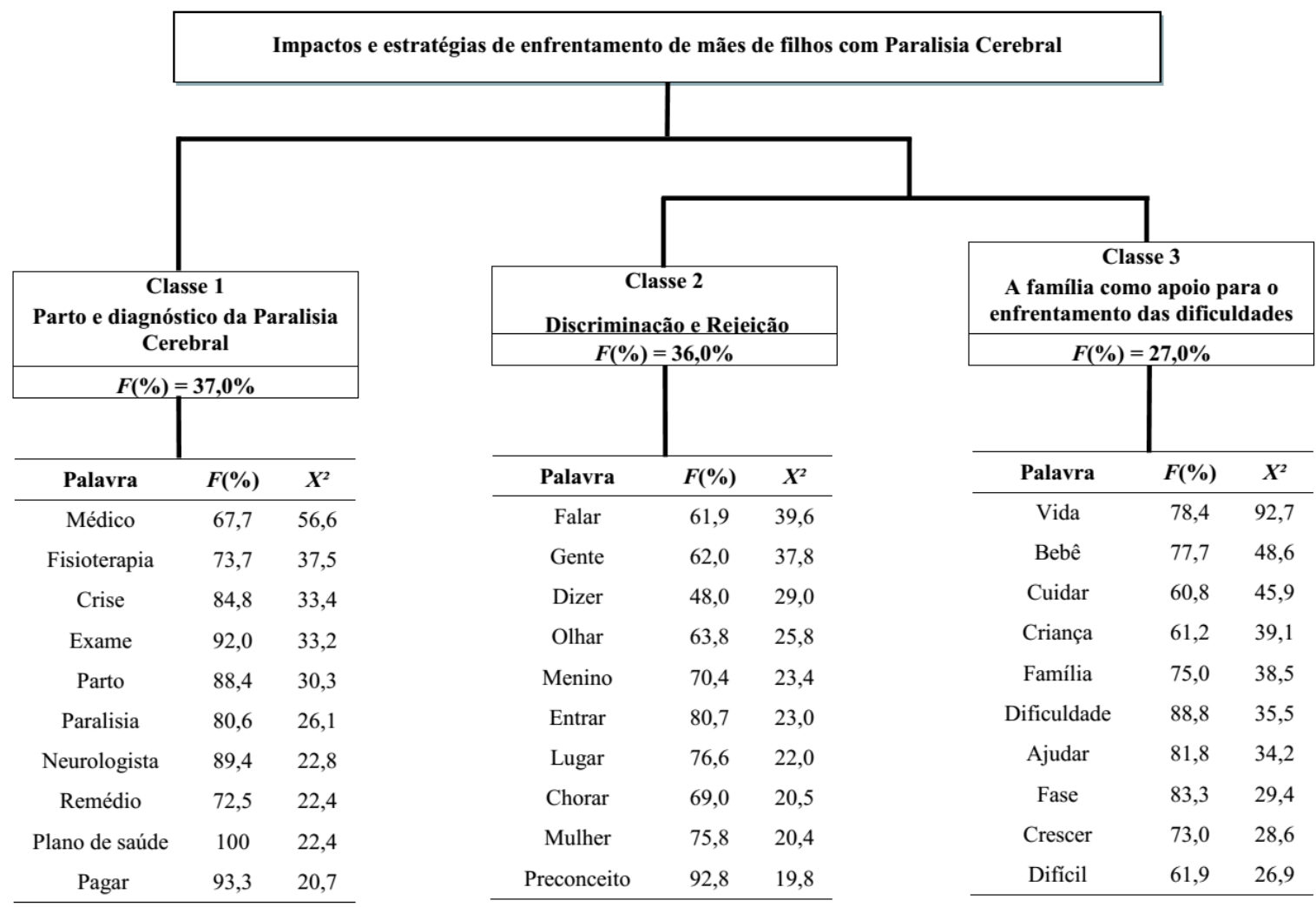

Nota: Todas as palavras com $p<0,001$.

Classe 1: Parto e diagnóstico da Paralisia Cerebral $(37,0 \%)$

Esta classe foi composta pelos discursos que giraram em torno de falas que englobavam o momento do parto e as primeiras informações sobre a PC, além das decisões a serem tomadas pelas mães. Algumas das palavras mais recorrentes foram: "médico", "fisioterapia", "crise", "exame", "parto", "paralisia", "neurologista", "remédio", "plano de saúde" (todas com p <
0,001). A partir dessas, elaborou-se uma sentença do discurso simbólico mais representativo da classe 1: "Foi a partir do parto que surgiram as primeiras crises da paralisia. A partir daí são exames, médicos, fisioterapia e a luta com os planos de saúde".

O momento do parto pode ser considerado o primeiro impacto na vida das mães, pois foi na maternidade que aconteceram as primeiras complicações: 
parto difícil, acompanhado das sequelas no filho, o que indicava que algo não havia ocorrido bem. Entretanto, elas disseram que demais esclarecimentos sobre o ocorrido não foram transmitidos pela equipe da maternidade. Por outro lado, houve a percepção por parte das genitoras de que 0 filho não nasceu bem: "(...) o médico me mostrou. Ele nasceu todo roxo, muito inchado e derramando liquido pela boca" (mãe 03, 29 a).

A falta de informação por parte dos profissionais possivelmente dificultou 0 enfrentamento do diagnóstico prévio e tratamentos iniciais adequados a PC, com consequentemente impacto na adaptação das mães, como se pode apreender a partir do relato de uma delas: "(...) eles não passaram essas informações: ele dava a crise, ficava roxo em casa..., eu ligava para todo mundo: 'socorram-me que meu filho está morrendo!' eu não sabia o que era. Eu não sabia como socorrê-lo" (mãe 03, 29 a). Tal situação de conflito e desconhecimento gerou angústia, inclusive com caráter de culpabilidade, 0 que torna evidente 0 impacto do sofrimento sobre a mãe.

É interessante salientar que se extrairmos algumas das principais expressões repetidas pelas mães, detectamos que os termos: "por que" (106 repetições); "que eu" (106 repetições); "que ele" (77 repetições); "ele não" (45 repetições) foram os mais comuns. Por meio dessas palavras apreendem-se questionamentos que elas se fazem e reações que manifestam: "porque eu?", "porque ele?" "ele não!": "(..) no começo, eu fiquei assim... não por ele, mas pela situação. Um pouco revoltada. Porque comigo, não é?" (mãe 06, 40 a ).

Geralmente, o momento em que os pais recebem o diagnóstico do filho é recheado de dúvidas, dificuldades e preocupação para com o futuro, o que tende a se incrementar com 0 cotidiano inicial de enfrentamento do quadro clínico da criança.
Pode haver questionamentos e reações dos mais diversos tipos, que embora esperados, devem ser avaliados na perspectiva da condição emocional das mães, pois a forma como elas lidam com a situação e o fato de questionar-se não indica necessariamente se 0 enfrentamento está ou não sendo saudável (Ahmadizadeh \& Mokhlesin, 2014; Krstic \& Oros, 2012).

Quanto à minimização do sofrimento, Petean e Murata (2000) salientaram a importância de esclarecimentos de profissionais de saúde sobre o diagnóstico da PC, para que ao sair do hospital as mães e os familiares saibam quais são as medidas que devem ser realizadas para 0 tratamento dos filhos. As autoras identificaram que informações complexas tornam-se vagas e confusas para 0 entendimento das mães, 0 que pode dificultar o tratamento e o diagnóstico correto em menor espaço de tempo. Adicionalmente, vale salientar que Lazcano et al. (2014), em estudo realizado no México, reuniram evidências empíricas de que ações focadas no provimento de informações adequadas para a capacitação para o cuidado tendem a reduzir de modo significativo o estresse derivado do cuidar. No estudo desses autores, a habilidade da resolução de problemas foi um elemento diferenciadamente favorável à adaptação mais saudável dos cuidadores.

Isso corrobora a posição de Gondim, Pinheiro e Carvalho (2009) ao destacarem que os profissionais de saúde devem qualificar as informações passadas sobre a PC aos familiares, de maneira a encorajar 0 enfrentamento objetivo da situação, para que estes consigam desenvolver melhores estratégias para lidar com as adversidades relativas ao cuidado no dia-a-dia. Inclusive, o investimento na melhoria da qualidade das informações tende a reverberar positivamente na qualidade de vida da própria pessoa com $\mathrm{PC}$, em um notório ganho secundário, tal qual fora reforçado 
por Bayrakli e Kaner (2012) e Whittingham et al. (2014).

Kohlsdorf e Costa Júnior (2008) frisaram que para melhor adaptação dos cuidadores de crianças em tratamento prolongado, é importante que equipes multiprofissionais façam o acompanhamento dos pais levando as informações necessárias sobre 0 tratamento adequado para os filhos. Diante disso, acredita-se que possivelmente algum nível de falta de clareza das informações por parte da equipe multiprofissional da maternidade tenha limitado a chance de uma resposta mais adaptativa frente ao impacto do diagnóstico. Portanto, salientase a importância das equipes de saúde como suporte para se compreender melhor o diagnóstico, causas e consequências da PC, 0 que auxilia as mães no cuidado inicial.

O processo de aceitação inicial por parte dos familiares maternos foi visto como positivo, como pode ser visto a seguir: "minha família aceitou desde o primeiro momento, graças a Deus. Minha família que me apoia e mim ajuda em tudo que eu precisar" (mãe 01, 29 a). Por outro lado, a aceitação dos familiares paternos foi vista como imparcial ou negativa, já que algumas mães relataram acontecimentos negativos à época: "(...) o tratamento entre os sobrinhos é diferente, o tratamento entre os netos é diferente... O pai e a mãe do meu marido tratam muito diferente e isso me dá muita raiva. Isso dá muita raiva porque todo mundo é tratado ali por igual, menos meu filho. Ele é sempre o excluído de tudo, sempre é esquecido" (mãe 03, 29 a).

A chegada de novo um integrante da família geralmente acontece com muitas expectativas. É esperado que a criança nasça com vigor, inteligência, saudável e perfeita. Quando nasce com alterações físicas ou neurológicas, a notícia é recebida pela família com perplexidade, podendo gerar conflitos e desestruturação familiar (Gondim et al., 2009). Em virtude de aspectos como esses, sabe-se que a família sofre no processo de aceitação da criança e também necessita de assistência $e$ informações referentes à PC (Bayrakli \& Kaner, 2012; Cestari, Barbosa, Carvalho, Melo, \& Studart, 2013; Krstic \& Oros, 2012).

Segundo Barbosa e Oliveira (2008), a mãe está mais propensa a desenvolver estresse ou problemas emocionais, visto que ela carrega um sentimento de culpa quando o "bebê perfeito" esperado por todos nasce com deficiência. Esse argumento pode ser visto na fala de uma mãe: "(...) a mãe do meu marido disse que quem tinha defeito era eu... Eu que sou doente. Se eu for engravidar, vai nascer outro doente pior que esse" (mãe 03, 29a). Porém, percebeu-se que as mães que receberam apoio e aceitação por parte dos familiares, alegaram sentir-se menos sobrecarregadas. Já as que perceberam a rejeição dos familiares frente à condição do filho, relataram sofrer com isso e sentiremse mais fadadas a assumir toda sobrecarga sozinha. Assim, tal qual é importante 0 apoio dos profissionais de saúde, o apoio e aceitação dos membros da família mostraram-se fundamentais na adaptação, aceitação e enfrentamento pelas mães.

Baltor e Dupas (2013) mencionaram que, mesmo inconformados com as restrições e impossibilidades dos filhos, os pais não desistem de buscar a melhor condição para eles. Com efeito, percebeu-se entre as mães a busca por desenvolver estratégias para continuar o cuidado, apesar das dificuldades da condição. Neste estudo, foi observado que algumas mães mantêm os tratamentos em dia e apegam-se à religião. Uma crença comum foi a de acreditar que mesmo o filho tendo limitações severas em virtude do diagnóstico, Deus pode fazer um milagre e reverter o quadro: "(...) eu vou confiar em Deus. Se Deus quiser, ele vai andar" (mãe 02, 29 a); "(...) minha filha está nas mãos de Deus. Se Deus achar que minha filha vai ter a oportunidade de andar, minha filha vai andar" (mãe 01, 29 a). 
Todavia, ao longo do tempo, as mães vão se dando conta de que o que foi repassado pelos profissionais de saúde sobre 0 diagnóstico do filho é irreversível. Assim, elas tendem a encarar a condição real chegando ao estado de resignação: (...) "Fui me dando conta que meu filho é especial. Eu disse: - Meu filho realmente não vai andar. 0 médico me disse que ele não iria andar, e ele não vai andar mesmo. Eu tenho que enxergar isso da maneira que realmente é a realidade." (mãe 10, 45 a).

As mães de crianças mais velhas pareceram que, com o crescimento do filho, passaram a avaliar a situação presente $e$ futura mais claramente baseadas em aspectos concretos relacionados às limitações e possibilidades de desenvolvimento na PC. Antes, enquanto crianças, a realidade parece ter sido confrontada de modo mais fantasioso, o que passou a ser encarado de maneira mais objetiva com o tempo. Isso apontou para um processo enfrentamento mais fortemente atrelado à ressignificação do contexto, com reavaliação positiva e maior focalização no problema. Tal aspecto também foi observado em outros estudos, sugerindo ser um conjunto de estratégias de maior impacto positivo na adaptação de mães aos desafios do cuidado de uma criança ou adolescentes com PC (Ahmadizadeh et al., 2015; Cheshire, Barlow, \& Powell, 2010; Kristic \& Oros, 2012; Marrón et al., 2013).

Após o diagnóstico, as mães receberam como principais recomendações a fisioterapia e o tratamento medicamentoso por tempo indeterminado. Tais recomendações podem ser vistas nas rememorações: "(...) Olhe... Vai ter que usar remédio controlado quando sair daqui. Vai ter que ter acompanhamento médico, fisioterapia. Vai ter que começar a fazer tudo devagar, vai ser lento. (mãe 03.29 a). Os tratamentos diários tornam-se desgastantes com o passar do tempo. É difícil para as cuidadoras conciliarem trabalho, atividades domésticas ou pessoais com os cuidados básicos da criança, além da rotina de administração de medicamentos e idas a médicos e sessões de fisioterapia. Segundo Ribeiro, Porto e Vandenberghe (2013), lidar com a fragilidade de uma pessoa com PC e conciliar o cuidado com outras exigências da vida dos cuidadores é estressante e pode levar a pessoa ao adoecimento.

As dificuldades são muitas e, durante esse processo, a renúncia da própria vida e a devoção pelo filho foi visto como uma missão a elas designada e que, por mais que seja desgastante, existe algo gratificante. A esse respeito, Silva et al. (2010) disseram que as mães que cuidam de um filho com necessidades especiais sentem-se gratificadas e que abdicar de outros papéis para cuidar do filho pode ser visto como uma função concernente ao papel materno. "(...) Tudo na vida da gente é Deus que sabe o que faz. A gente só esta aqui para cuidar deles..." (mãe 01, 29 a).

Em suma, viu-se que a rotina de mães de filhos com PC é relatada como desgastante e impactada pela qualidade das informações e assistência que elas recebem para executar o cuidado. Por fim, ainda foi notado que as cuidadoras dependem de suporte emocional dos familiares no processo de aceitação, o que nem sempre ocorre de modo automático e positivo.

\section{Classe 2: Discriminação e rejeição $(36,0 \%)$}

Essa classe trouxe como tema principal a discriminação enfrentada pelas mães por parte da sociedade e a rejeição inicial delas mesmas para com os filhos, sendo ambas formas de sofrimento. As palavras mais importantes desta classe foram: "falar", "gente", "dizer", "olhar", "menino", "lugar", "entrar", "chorar", "mulher", e "preconceito" (todas com $p<0,001$ ). Elaborou-se, assim, - seguinte discurso simbólico para representar essa classe: "Tem gente que 
passa a olhar o menino com preconceito quando entro nos lugares".

Neste estudo, as mães relataram que uma das causas do sofrimento é 0 comportamento das pessoas em determinados locais. Com isso, inicialmente elas sentem-se impotentes e culpadas como pode ser visto nas falas seguintes: "(...) uma vez aconteceu quando eu fui para uma clinica com ele para pediatra e uma mãe que estava com uma criança lá, a menina foi pegar nele para mexer. Eu fiquei brincando com a menina, a mãe puxou-a assim, tipo: saia daí por que ele tem baba e essa baba vai passar doença para você. Isso me irritou" (mãe 03, 29 a);"(...) 0 preconceito machuca a gente muito, muito! Muitas vezes a gente chega assim nos lugares, as pessoas olham, parece que está chegando um monstro" (mãe 06, 40 a).

Dados culturais e históricos mostram que ainda é comum que as pessoas com deficiência sejam tratadas como anormais e, assim, passem a ser discriminadas e estigmatizadas socialmente (Baykrali \& Kaner, 2012; Silva et al., 2010). Esse fato reflete não só no ajustamento materno (Ahmadizadeh \& Mokhlesin, 2014), mas também causa marcante degradação no ajustamento das próprias pessoas com PC (Calver et al., 2015; Shikako-Thomas, Lach, Majnemer, Nimigon, Cameron, \& Shevell, 2009). Segundo as mães entrevistadas e com base na literatura, as pessoas tendem a olhar para uma criança com necessidades especiais com preconceito e isso, principalmente para a mãe que é a principal cuidadora, é um obstáculo a ser enfrentado. Nem sempre elas estão habilitadas a enfrentar 0 fato de ouvir termos com conteúdos discriminatórios que possam ofendê-las ou causar-lhes sofrimento (Baltor, Borges, \& Dupas, 2013).

De acordo com os relatos, com o passar do tempo é que as mães conseguem lidar com esse tipo de adversidade, geralmente utilizando argumentos baseados nos conhecimentos adquiridos sobre a PC. 0 conhecimento serviu, então, para ajudar as próprias mães a enxergar a deficiência do filho como um caso especial, e ademais, capacitá-las para defender o filho ou a ignorar os comportamentos ofensivos emitidos pelas pessoas no dia-a-dia. "(...) eu fingi que não ouvi, aí ela aproximou-se novamente, pegou na mãozinha dele e disse: ele é doentinho né? Eu falei: - Não. Ele não está doente. Aí ela falou: ai meu Deus... Ele é doentinho. Ele anda? Eu disse:- Não. Ele se senta? Eu disse: - Não. Então, ele é doentinho. Aí eu disse:- Não. Ele tem uma deficiência, mas ele não está doente porque ele não está com febre. Aí ela falou: - Ai Meu Deus... Antes Deus levasse... não anda, não come sozinho, não faz nada. E eu disse:- Olhe, a senhora tem vontade de morrer só por que a senhora esta ficando idosa" (mãe 10, 45 a). Tais estratégias serviram para que as mães pudessem lidar melhor com situações que as deixavam em conflito. Consequentemente, ajudou a enfrentar a discriminação de forma menos desadaptativa, uma vez que alegaram ter elaborado uma forma menos estressante de lidar com a ação/reação de outras pessoas ao se depararem com seus filhos (Baltor \& Dupas, 2013; Vieira, Mendes, Frota, \& Frota, 2008). Pode-se verificar isso na seguinte fala. "(...) já acostumei. Nem reclamo mais. Antes eu falava, discutia, mas agora eu não falo mais nada... Acostumei. Cada um tem o seu jeito de pensar. Já acostumei com isso" (mãe 03, 29 a).

Ainda nessa categoria foram revelados conteúdos referentes não só à rejeição ou discriminação por parte dos outros, mas também houve falas que mencionaram a rejeição de seus próprios filhos após 0 nascimento, frente algumas características da PC (olhos grandes e cabeça pequena). De acordo com as mães, a rejeição inicial se deu devido o impacto e desconhecimento da doença, o que gerou estranhamento, semelhante ao que acontece com algumas pessoas no dia-a-dia: "(...) quando ele 
nasceu eu ia jogar ele no chão... A cabeça pequenininha, o olhão... Aí, eu acho que foi porque nasceu fora do tempo. Aí fica feinho mesmo." (mãe 02, 29a). Para Sousa e Pires (2003), esses sentimentos também podem ser caracterizados como uma forma que a mãe desenvolve para expressar sua revolta diante do filho que não nasceu perfeito aos seus olhos e aos da sociedade.

Em resumo, na classe 2 foram evidenciadas algumas dificuldades enfrentadas pelas mães na trajetória do cuidado. A discriminação foi um obstáculo que fez com que elas tenham se sentido impotentes e despreparadas para reagir, mas também para compreender que as pessoas comumente discriminam também por falta de conhecimentos necessários para encararem as diferenças com naturalidade.

Classe 3: A família como apoio no enfrentamento das dificuldades $(27,0 \%)$

Nesta classe são apresentados conteúdos referentes à família como matriz de apoio e suporte no enfrentamento das dificuldades inerentes ao cuidado e dedicação exclusiva das mães. As palavras mais representativas foram: "vida", "bebê", "cuidar", "criança", "família", "dificuldade", "ajudar", "fase", "crescer" e "difícil" ( $p<0,001)$. A partir dessas palavras criou-se 0 seguinte discurso simbólico: "Por toda vida meu filho será um bebê a ser cuidado, não só por mim, mas também pela minha família".

A noção de cuidar do filho como sendo uma criança até mesmo nas fases posteriores foi internalizada a partir do diagnóstico quando os médicos disseram que um filho com PC seria sempre como uma criança no que se refere aos cuidados. Essa noção pode ser vista nas falas das mães dos filhos com 16 e 18 anos: "(...) eu achava que ele era um bebê, sempre seria um bebê. Eu tinha a brincadeira de dizer: você é um homem, mas em mim, dentro de mim, ele ainda era um bebê" (mãe 08, 41 a); “(...) Ele é uma criança muito tranquila.
Assim... Eu não tive muita dificuldade... Só às vezes que ele está um pouco agitado. Minha dificuldade agora está sendo a do peso, pois ele está pesado. Eu sempre preciso de alguém para me ajudar, para dar banho, mas eu ainda consigo" (mãe 07,40 a).

Por se tratar de uma condição crônica e permanente, a criança com PC demanda de cuidados contínuos e depende do seu cuidador para ministrá-los, principalmente quando se trata de um quadro etiologicamente grave (Leite \& Prado 2004; Raina et al., 2005). Baltor e Dupas (2013) já haviam tratado disso, citando que as dificuldades intensificam-se em vários âmbitos, principalmente: financeiro, dificuldades de mobilidade e acessibilidade, pois elas precisam recorrer a diferentes serviços terapêuticos e na maioria das vezes dependem do transporte publico 0 qual não é adequado às necessidades de cadeirantes. $O$ relato a seguir tenta evidenciar esse discurso:"(...)Agora que ele está crescendo, as dificuldades vão aparecendo. As pessoas não respeitam um cadeirante e com isso me sinto muito mal... estou evitando sair com ele de ônibus" (mãe 06,40 a). Vê-se que passado o momento de adaptação inicial, outros agravantes passam a demarcar momentos cruciais na vida do cuidador, o que mostra que a trajetória é marcada por readaptações.

Frente à intensificação das dificuldades geradas pelo crescimento do filho, assim como no início da adaptação ao diagnóstico, as mães relataram que contam com o apoio ainda maior dos familiares para continuar realizando atividades que antes elas conseguiam realizar sozinhas, a exemplo de trocar de roupa, dar banho, colocar na cama ou na cadeira de rodas. Por outro lado, ainda que necessite de ajuda da família, as mães disseram que não confiam entregar 0 filho para ser cuidado por qualquer pessoa, acreditando que apenas elas sabem administrar os cuidados. O máximo que fazem é eleger membros de confiança para 
substituí-las em alguns momentos de ausência.

Assim como mencionaram Matsukura et al. (2007), os familiares tendem a ser os principais responsáveis pelo suporte emocional e prático dos cuidadores e, geralmente, os eleitos são os maridos, mãe, irmãs, comadres, primas ou outros filhos, tal qual se vê nos relatos a seguir: "(...) Só deixo ele com minha irmã, com minha prima ou com a madrinha dele, somente. Ninguém mais fica com ele. Ninguém! Não confio em ninguém chegar perto dele. Tenho medo de todo mundo que chega perto dele." (mãe 03, 29 a).

A preocupação de que 0 filho seja maltratado ou descuidado faz com que elas sofram e continuem delegando recomendações: "(...) Para mim, eu que tenho que cuidar dele o tempo todo. Quando eu preciso sair para resolver alguma coisa, para não levar, deixo com alguém. Mesmo assim eu fico no sentido, ligando: - Ele já comeu? Ele esta dormindo? Ele está bem? Ele está tendo crises? Fico no sentido." (mãe 03, 29a). A superproteção, neste caso, pode ser um fator gerador de ansiedade e insegurança, 0 que faz com que as mães não consigam desvincular-se do seu papel de cuidadora, ainda que por pouco tempo e mesmo percebendo as suas limitações e necessidades de ajuda (Baltor \& Dupas, 2013; Silva et al., 2010).

Enfim, foi visto que 0 sofrimento resultante da sobrecarga do cuidado tende a aumentar à medida que 0 filho vai crescendo. Logo, é importante que desde 0 início os familiares sejam chamados a ajudar, ampliando o suporte às mães. Ademais, formas distintas de enfrentamento são observadas ao longo do crescimento, pois a rotina torna-se mais árdua à medida que as mães passam a depender do transporte público adaptado e há maior necessidade de recursos financeiros para os gastos com a assistência a saúde.

\section{Análise Geral das Classes}

0 presente estudo objetivou investigar as mudanças que ocorrem nas vidas de mães cuidadoras de filhos com PC, os impactos nelas causados devido à sobrecarga do cuidado e as estratégias de enfrentamento desenvolvidas para lidar com os principais desafios.

$\mathrm{Na}$ primeira classe, os discursos englobaram falas referentes ao parto, diagnóstico, primeiras informações sobre a PC e decisões a serem tomadas pelas mães posteriormente. Esses momentos foram marcados pelos impactos do diagnóstico, gerando incertezas, medo, rejeição e tentativas de adaptação. Observou-se que no nascimento e quando receberam o diagnóstico dos filhos, as mães se sentiram pouco informadas a respeito da $\mathrm{PC}$, relatando terem demandado maiores esclarecimentos sobre o tratamento. Assim, viu-se que a falta de informações claras possivelmente resultaram na postergação do tratamento do filho e isso contribuiu com a angústia delas, especialmente por não terem recebido um direcionamento mais objetivo quanto ao que fazer na situação.

Percebeu-se, ainda, que apesar de saber das limitações e impossibilidades que a PC acarreta no desenvolvimento do filho, as mães tenderam a se apegar à fé religiosa, criando a expectativa de que 0 diagnóstico do filho será revertido. Tal estratégia pareceu facilitar a adaptação de algumas mães nos anos iniciais dos filhos, visto que, passado este momento primeiro de enfrentamento, os discursos passaram a ser mais carregados de resignação.

A segunda classe trouxe principalmente a discriminação da sociedade $e$, secundariamente, a rejeição inicial das próprias mães, sendo esses alguns fatores de sofrimento comumente enfrentados por 
elas. A rejeição por parte da mãe foi impactada para a mudança a partir da aquisição de conhecimento sobre a PC e por meio do apoio familiar. Com a contribuição dessa modificação de perspectiva, a discriminação por parte da sociedade passou a ser confrontada, na tentativa de mostrar para as pessoas que uma criança com PC, apesar de requerer cuidados especiais, pode desenvolver-se e viver próximo - dentro de suas limitações do que se espera para pessoas que não possuem esse tipo de deficiência.

Já a terceira classe tratou da família como principal fonte de apoio nos diferentes momentos da trajetória do cuidado, os quais foram marcados por uma dinâmica de adaptações e readaptações. Além do sofrimento psicológico, a sobrecarga física se constituiu como agravante, uma vez que à medida em que a criança se desenvolveu, as atividades a serem realizadas com ela se tornaram mais difíceis, além do marcante aumento dos gastos financeiros e das dificuldades de locomoção. Em meio às implicações, as mães relataram se tornar cada vez mais propensas ao estresse e adoecimento. Assim como visto na primeira classe, julgou-se importante pontuar a necessidade de que se desenvolvam programas educativos nos serviços de saúde, a fim de que os profissionais de saúde possam mais bem atender e orientar as mães sobre a PC, já que o diagnóstico e as primeiras mudanças advindas foram relatados como períodos de maior transformação na vida das mães.

Uma limitação que se observou nesta pesquisa se deveu ao fato de a amostra ter sido composta por mães de crianças em fases do desenvolvimento distintas. Ao longo do trabalho, o tempo de cuidado se revelou uma variável possivelmente central para diferenciação dos discursos, ainda que não tenha sido considerada a priori neste trabalho. Logo, sugere-se que próximas pesquisas investiguem de modo longitudinal a vivência de mães de filhos com PC (infância, adolescência e idade adulta, por exemplo), pois isso parece influenciar a trajetória do cuidado.

No que diz respeito a futuros estudos, aponta-se como de fundamental importância o desenvolvimento de trabalhos voltados ao modo como os pais de crianças com PC (e não apenas as mães) enfrentam as situações estressoras e desenvolvem sua adaptação, uma vez que no decorrer deste estudo os pais (independentemente da conjugalidade) foram descritos como ausentes ou detentores apenas das responsabilidades financeiras.

Finalmente, no plano prático, viu-se a premência por maior incentivo à criação de grupos de apoio nas próprias instituições de assistência, visto que as mães cuidadoras possuem déficit de horários e podem ter severas restrições de renda. Especialmente entre as mães entrevistadas, esse aspecto limitou a possibilidade de um acompanhamento psicológico fora dos locais em que seus filhos são assistidos. 


\section{REFERÊNCIAS}

Ahmadizadeh, Z., \& Mokhlesin, M. (2014). Factors with affect the depression of mothers with cerebral palsy child. Iranian Reabilitation Journal, 22, 1-6.

Ahmadizadeh, Z., Rassafiani, M., Khalili, A. M., \& Mirmohammadkhani, M. (2015). Factors associated with quality of life in mothers of children with cerebral palsy in Iran. Hong Kong Journal of Occupational Therapy, 25, 15-22.

Baltor, M. R. R., \& Dupas, G. (2013). Experiências de famílias de crianças com paralisia cerebral em contexto de vulnerabilidade social. Revista LatinoAmericana de Enfermagem, 21(4), 2-8.

Baltor, M. R. R., Borges, A. A., \& Dupas, G. (2013). Interação com a criança com paralisia cerebral: Comunicação e estigma. Escola Anna Nery Revista de Enfermagem, 18, 47-53.

Barbosa, A. J. G., \& Oliveira, L. D. (2008). Estresse e enfrentamento em pais de pessoas com necessidades especiais. Psicologia em Pesquisa, 2(2), 36-50.

Bayrakli, H., \& Kaner, S. (2012). Investigating the factors affecting resiliency in mothers of children with and without intellectual disability. Educational Sciences: Theory \& Practice, 12, 936-943.

Brasil (2015). Lei de $n^{0} 13.146$, de 06 de Julho de 2015. Dispõe sobre a inclusão da pessoa com deficiência (Estatuto da Pessoa com Deficiência). Diário Oficial da União, 06 de Julho de 2015, Livros I e II, 2015.

Brehaut, J. C., Kohen, D. E., Raina, P., Walter, S. D., Russell, D. J, Swinton, M., O'Donnell, M., \& Rosenbaum, P. (2004). The health of primary caregivers of children with cerebral palsy: How does it compare with that of other Canadian caregivers? Pediatrics, 114, 182-191.

Camargo, B. V., \& Justo, A. M. (2013). IRAMUTEQ: Um software gratuito para análise de dados textuais. Temas em Psicologia, 21, 513-518.

Camargo, R. C. V. F. (2010). Implicações na saúde mental de cuidadores de idosos: Uma necessidade urgente de apoio formal. SMAD, Revista Eletrônica Saúde Mental Álcool e Drogas, 6, 232254.

Camargos, A. C. R., Lacerda, T. T. B., Viana, S. O., Pinto, L. R. A., \& Fonseca, M. L. S. (2009). Avaliação da sobrecarga do cuidador de crianças com paralisia cerebral através da escala Burden Interview. Revista Brasileira de Saúde Materno Infantil, 9, 31-37.

Cestari, V. R. F., Barbosa, I. V., Carvalho, Z. M. F., Melo, E. M., \& Studart, R. M. B. (2013). Evidências científicas acerca da paralisia cerebral infantil. Cogitare Enfermagem, 18, 796-802.

Cheshire, A., Barlow, J., \& Powell, L. (2010). Coping using positive reinterpretation in parents of children with cerebral palsy. Journal of Health Psychology, 15, 801810.

Colver, A., Rapp, M., Eisemann, N., Ehlinger, V., Dickinson, O. H., Parkinson, K., Nystrand, M., Fauconnier, J., Marcelle M., Michelsen, I. S., \& Amaud, C. (2015). Self-reported quality of life of adolescents with cerebral palsy: A crosssectional and longitudinal analysis. The Lancet, 385,705-716.

Ferreira, H. P., Martins, L.C., Braga, A. L. F., \& Garcia, M. L. B. (2012). 0 impacto da doença crônica no cuidador. Revista Brasileira de Clínica Médica, 10, 278284.

Fonseca, N. R., Penna, A. F. G., \& Soares, M. P. G. (2008). Ser cuidador familiar: Um estudo sobre as consequências de assumir este papel. Physis: Revista de Saúde Coletiva, 18, 727-743.

Gondim, K. M., Pinheiro, P. N. C., \& Carvalho, Z. M. F. (2009). Participação das mães no tratamento dos filhos com paralisia cerebral. Revista Rene, 10, 136-144. 
Jaques, K. C., Drumond, N. R., Andrade, S. A. F., Junior, E. P. C., \& Toffoll, W. C. (2010). Eficácia da hidroterapia em crianças com encefalopatia crônica não progressiva da infância: Revisão sistemática. Fisioterapia em Movimento, 23, 53-61.

Kohlsdorf, M., \& Costa Junior, A. L. (2008). Estratégias de enfrentamento de pais de crianças em tratamento de câncer. Estudos de Psicologia, 25, 417-429.

Krstic, T., \& Oros, M. (2012). Coping with stress and adaptation in mothers of children with cerebral palsy. Medicinski Pregled, LXV, 373-377.

Lazcano, M. F., Cura, A. M., Aranda, R. M. J., Heras, R. H., Elizondo, G. T., \& Garza, B. F. (2014). Impacto de una intervención psicosocial en la carga del cuidador de niños con parálisis cerebral. Atentión Primaria, 46, 401-407.

Leite, J. M. R., \& Prado, G. F. (2004). Paralisia cerebral aspectos fisioterapêuticos e clínicos. Neurociências, 12, 41-45.

Mancini, M. C., Fiúza, P. M., Rabelo, J. M., Magalhães, L. C., Coelho, Z. A. C., Paixão, M. L., Contijo, A. P. B., \& Fonseca, S. T. (2002). Comparação do desenvolvimento de atividades funcionais em crianças com desenvolvimento normal e crianças com paralisia cerebral. Arquivos de Neuro-Psiquiatria, 60, 446-452.

Manuel, J.,Naughton, M. J, Balkrishnan, R., Smith, B. P., \& Koman, L. A. (2003). Stress and adaptation in mothers of children with cerebral palsy. Journal of Pediatric Psychology, 28, 197-201.

Marrón, M. E., Ripoll R. D., Boixadós, M., Nieto, R., Guillamón, N., \& Gomez, B. (2012). Burden of caregivers of children with cerebral palsy: Predictors and related factors. Universitas Psychologica, 12, 767-777.

Matsukura, T. S., Martuurano, E. M., Oishi, J., \& Borasche, G. (2007). Estresse e suporte social em mães de crianças com necessidades especiais. Revista
Brasileira Educação Especial, 13, 415442.

Ones, K., Yilmaz, E., Cetinkaya, B., \& Caglar, N. (2005).Assessment of the quality of life of mothers of children with cerebral palsy (primary caregivers). Neurorehabilitation and Neural Repair, 19, 232-237.

Petean, E. B. L., \& Murata, M. F. (2000). Paralisia cerebral: Conhecimento das mães sobre o diagnóstico e o impacto desta na dinâmica familiar. Paidéia, 10, 40-46.

Raina, P., O'Donnell, M., Rosenbaum, P., Brehaut, J., Walter, D. S., Russell, D., Swinton, M., Zhu, B. \& Wood, E. (2005). The health and well-being of caregivers of children with cerebral palsy. Pediatrics, 115, 626-636.

Ribeiro, M. F. M., Porto, C. C., \& Vandenberghe, L. (2013). Estresse parental em famílias de crianças com paralisia cerebral: Revisão integrativa. Ciência \& saúde coletiva, 18, 17051715.

Shikako-Thomas, S. K., Lach L., Majnemer, A., Nimigon, J., Cameron, K., \& Shevell, M. (2009). Quality of life from the perspective of adolescents with cerebral palsy: "I just think I'm a normal kid, I just happen to have a disability". Quality of Life Research, 18, 825-832.

Silva, C. X., Brito, E. D., Sousa, F. S., \& França, I. S. X., (2010). Criança com paralisia cerebral: Qual o impacto na vida do cuidador? Revista Rene, 11, 204-214.

Simões, C. C., Silva, L., Santos, M. R., Misko, M. D., \& Bousso, R. S. (2013). A experiência dos pais no cuidado dos filhos com paralisia cerebral. Revista Eletrônica de Enfermagem, 15, 139145.

Sousa, B. C. S., \& Pires, A. (2003). Comportamento materno em situação de risco: Mães de crianças com paralisia cerebral. Psicologia, Saúde \& Doenças, 4, 111-130.

Vieira, B. G. N., Mendes, C. N., Frota, P. C. M. L., \& Frota, A. M. (2008). O 
cotidiano de mães com crianças portadoras de paralisia cerebral. Revista Brasileira em Promoção da Saúde, 21, 55-60.

Whittingham, K., Sanders, M., Mckinlay, L., \& Boyd, N., R. (2014). Interventions to reduce behavioral problems in children with cerebral palsy: An RCT. Official Journal of the American Academy of Pediatrics, 133, 1-9.

Wijesinghe, J. C., Hewage, C. G., \& Fonseka, P. (2014). Prevalence and predictors of psychological problems among principal caregivers of children with cerebral palsy in Galle, Sri Lanka. Journal of the College of Community Physicians of Sri Lanka, 19, 8-17. 